\title{
Gasoline hybrid pneumatic engine for efficient vehicle powertrain hybridization
}

\author{
Zlatina Dimitrova ${ }^{a}$, François Maréchal $^{b}$ \\ ${ }^{a}$ Ecole Polytechnique Fédérale de Lausanne, Lausanne, Switzerland, zlatina.dimitrova@epfl.ch \\ ${ }^{b}$ Ecole Polytechnique Fédérale de Lausanne, Lausanne, Switzerland, francois.machechal@epfl.ch
}

\section{Highlights:}

- The hybrid pneumatic powertrain is an alternative solution for hybridization.

- The main advantages are the low cost and the direct transmission of the torque.

- The hybrid pneumatic powertrain suits for urban driving and mild hybridization.

- An efficiency improvement of $50 \%$ is reached for urban driving and C Segment vehicle.

- The $\mathrm{CO} 2$ emissions on the urban cycle are very low - only $51 \mathrm{~g} \mathrm{CO}_{2} / \mathrm{km}$.

\section{Abstract:}

The largest applied convertors in passenger cars are the internal combustion engines - gasoline, diesel, adapted also for operating on alternative fuels and hybrid modes. The number of components that are necessary to realize modern future propulsion system is inexorably increasing. The need for efficiency improvement of the vehicle energy system induces the search for an innovative methodology during the design process.

In this article the compressed air is investigated as an innovative solution for hybridization of small gasoline engine. The combination of a conventional IC engine and a pneumatic short-term storage system is an interesting approach to achieve lower fuel consumption. Instead of using a battery, a hybrid pneumatic vehicle uses a robust and inexpensive air pressure tank for energy storage. The fuel consumption benefit of the hybrid air system is assessed and the vehicle usages leading to the maximal fuel consumption benefits of the hybrid pneumatic powertrain are investigated.

The hybrid pneumatic concept is applied on a largely deployed C Segment commercial vehicle with 3 cylinder gasoline engine. The lowest fuel consumption results are investigated on the usage of this vehicle.

Key words:

Hybrid pneumatic engine, Vehicle hybridization, ICE efficiency

\section{Nomenclature:}

\section{Charge Valve}

\section{CVT Continuously Variable Transmission}

HPE Hybrid Pneumatic Engine

HPP Hybrid Pneumatic Powertrain

ICE Internal Combustion Engine

MGB Manual Gear Box

NA Natural Aspirated

NEDC New European Driving Cycle 


\section{Introduction:}

With the increasing trend of mobility of the human population, vehicles have to face the problem of primary energy resources scarcity. The vehicles need higher efficiency and better adaptation to the alternative energy sources [1]. The need to improve the efficiency of the vehicle energy system motivates the search for innovative solutions during the design process [2].

Price vs $\mathrm{CO}_{2}$ emission

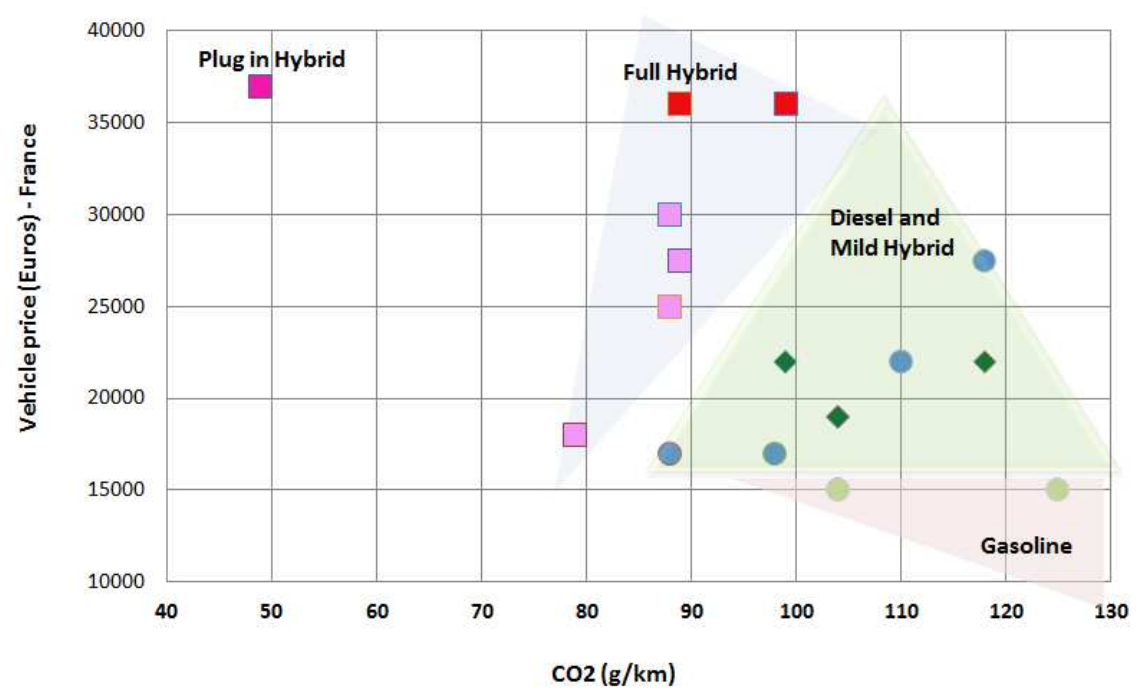

Figure 1 : Price vs $\mathrm{CO}_{2}$ emission of different hybridizations [3]

The main way for vehicle efficiency improvement that the automotive industry takes in the moment is the electrification of the vehicle powertrains [4], [5]. The hybrid electric vehicles, with different degree of electrification of the powertrain proliferate. The introduction of the electric components in the powertrain leads to increased cost and mass of the vehicles. This is especially due to the relatively low energy density capacity of the high voltage battery. The best storage potential available in serial production is the Li- Ion battery with energy density of $90 \mathrm{Wh} / \mathrm{kg}$ [6]. The efficiency/cost balance of the thermal and hybrid electric vehicles is represented on Figure 1.

One can see that there is a technological gap in the zone low CO2 emissions (below $90 \mathrm{~g} / \mathrm{km}$ ) and vehicle cost between 15000 and 25000 euros.

This article proposes a modellization methodology, based on energy balance calculation, for design of an alternative low cost powertrain with mild hybridization.

The best fuel consumption reduction is researched as alternative of the power boost of turbocharged four cylinder engines, highlighted by several researchers [7]. Other researchers [8] propose a hybrid pneumatic engine concept on 4 cylinders engine, with two air tanks and show experimental results with at least $70 \%$ of fuel improvement on stationary test bench conditions.

In this article the efficiency concept is developed on a small 1.2 liter 3 cylinders natural aspirated gasoline engine, with just one compact air tank, and after the vehicle integration, the best customers' usages are researched under dynamic conditions. The major contribution of the article is to bring a model that is used to estimate the fuel consumption benefit on a C- 
Segment Vehicle, which is one on the most popular categories of vehicles and targets the price zone.

\section{Pneumatic hybrid engine systems}

The combination of a conventional IC engine and a pneumatic short-term storage system is an interesting approach to achieve lower fuel consumption. Instead of using a battery, a hybrid pneumatic vehicle uses a robust and inexpensive air pressure tank for energy storage. The internal combustion engine is able to run in purely pneumatic modes, acting as a pneumatic pump or motor without fuel injection. The resulting concept is called Hybrid Pneumatic Engine (HPE) [6]. The concept appears in 1999 studied as new cycle opportunities for automotive engine [9]. Firstly, its efficiency estimations are done by simulations [10] and then the concept is realized for fuel reduction potential estimation [11]. Also different operations modes and possibilities to exploit the HPE for engine downsizing and "maximum torque at low rotation speed" are highlighted in [7]. An architecture using two air tanks is presented and explored on test bench in [8].

The concept allows recuperating some of the energy that is otherwise lost when braking and the elimination of the most inefficient engine operating point is possible. Moreover, it is an ideally complements for a downsized or supercharged engine. Since the air is provided to the cylinder by a fully variable charge valve, the torque can be raised from idling to full load, from one engine cycle to the next i.e. in the shortest possible time. The hardware configuration necessary for a directly connected HPE includes an additional valve in the cylinder head, which is connected to the pressure tank. A fully variable actuation of the valve is mandatory (Figure 2). This valve is called charge valve (CV) and is the link between the cylinder and the air tank.



Figure 2 : Schematic of concept [12]

The precision and the dynamic performances of this charge valve are extremely important for the concept viability. The pneumatic energy needs to be conserved in the tank. So the number of parameters for accurate system modeling is increasing and an appropriated methodology is needed.

The price vs $\mathrm{CO}_{2}$ emission balance of the standard way to reach mild hybridization by electrification is situated on Figure 1. The study presents the hybrid pneumatic concept and the simulation results of the efficiency improvement of a small gasoline engine, operating in hybrid pneumatic modes. The guide line of the study is to research the maximal efficiency improvement. The hybrid pneumatic gasoline powertrain is investigated on C- Segment 
commercial vehicle. The article proposes a modeling methodology, which considers all parameters for vehicle powertrain design. First simulations are applied on real vehicle and are proposed in this article. The simulation model is then the basis to study the optimal design configuration of the hybrid pneumatic powertrain as a function of the vehicle usage i.e, the vehicle driving cycles.

\section{Specific energy}

The energy stored in a pressure tank of fixed volume is the internal energy of the air contained in the tank. The maximum energy content is thus obtained at the maximum pressure level that the compression device used for pumping air into the tank can achieve. Since in an HPE the compression device is the engine used as pneumatic pump, the maximum tank pressure is generated by the engine compression ratio. According to Guzzella [6] the energy value of $6.28 \mathrm{~kJ} / \mathrm{l}$ results in compressed air. Compared to the energy density of the gasoline, the value is 5000 times smaller, so no interest for own vehicle propulsion is seen.

This article examines a parallel thermal hybrid pneumatic powertrain (HPP). In comparison with the well-known hybrid electric powertrain, the HPP is relatively recent research presented in [6], [12]. The electric components of the hybrid electric powertrain, especially the high voltage battery are expensive and their production and end-of-life phases are not so environmentally friendly. Pneumatic powertrains are gaining interest as an alternative method for powertrain hybridization [13], as they offer potential alternative in the range of small middle hybridization, to these drawbacks. The idea in the HPP is to use the engine cylinders and pistons to pump and receive air to and from the air tank. The pistons are recuperating or producing the force, transferred to the engine shaft. The HPP has two different energy sources and can be considered as simplified parallel hybrid, because only the engine shaft provides the link to the drive shaft (Figure 3).

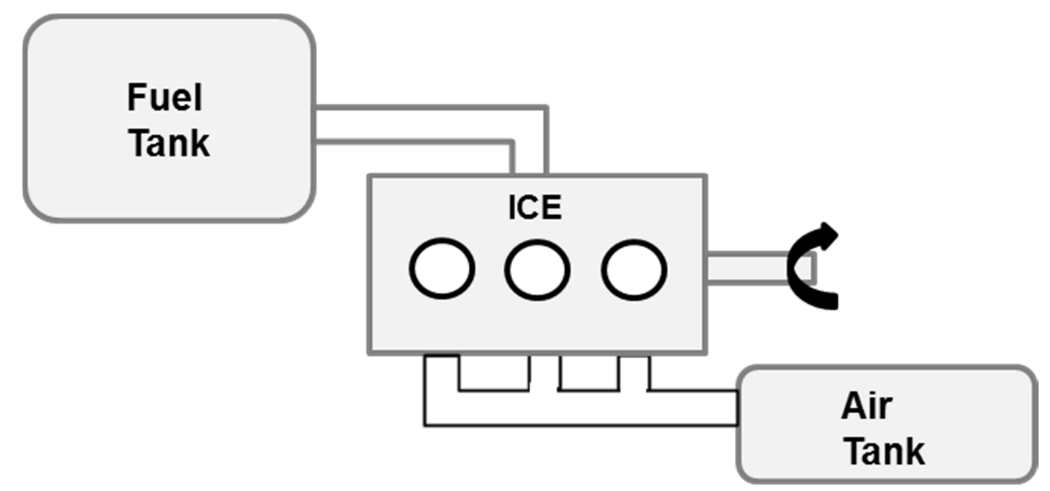

Figure 3 : Pneumatic hybrid powertrain with 3 cylinders engine

In the literature the exploration of the compressed air storage is related to the fuel consumption improvement and the cost reduction for vehicle powertrain applications [14], [15]. Also the compressed air is an efficient technology for diesel engines operating strategies and low cost storage tanks, applied in the power generation domain [16], [17].

\section{Operating modes:}

Pneumatic engines can be used in four- and two-stroke cycles (Figure 4). 


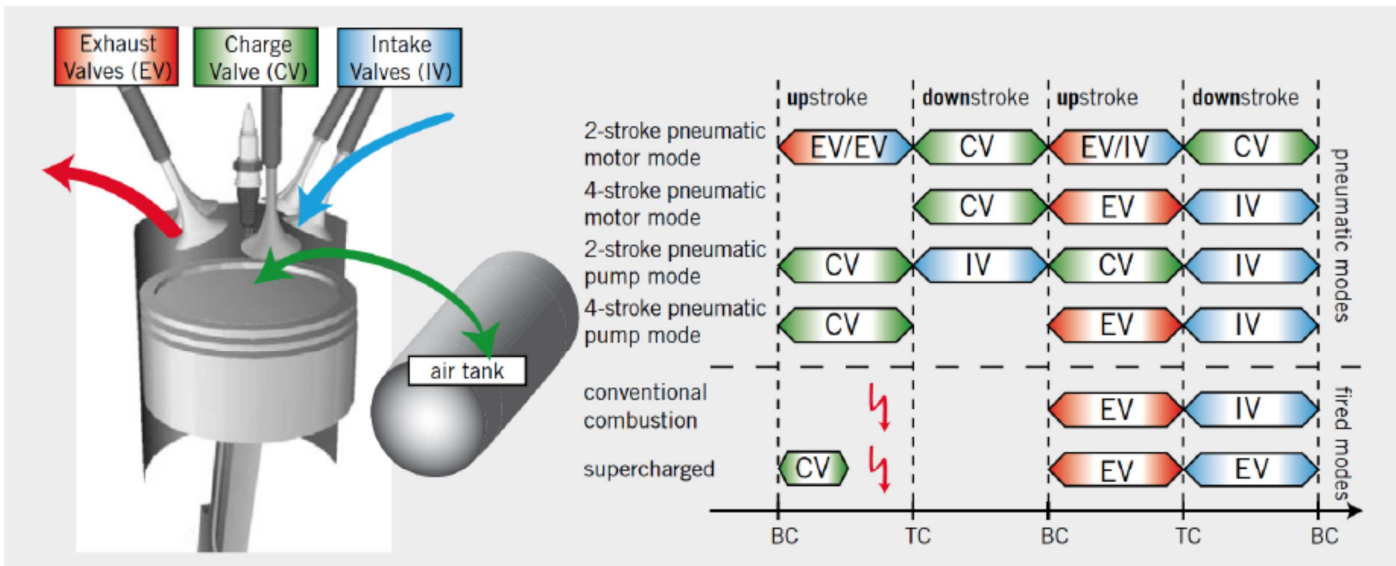

Figure 4 : Principle of pneumatic hybridation [11]

The compressed air can be used in two different ways. The first uses the air as assistance to the conventional combustion cycle. In the second one all fuel supply of the engine is cut off and the engine is powered by the compressed air alone. One distinguishes combustions modes and purely pneumatic modes, described below.

\section{1/ Combustion modes:}

- Conventional ICE mode: this is the main operating mode for HPE, based on Otto cycle

- Pneumatic supercharged mode: for turbo compressed engines sudden increases of air demand can cause a turbocharger lag that the HPE can cover by injection of compressed air in the compression stroke.

- Pneumatic undercharged mode: when the air tank pressure and torque demand are low, the excess air in the cylinder can be used to recharge the tank during the compression phase

The last two modes are not used in this study.

\section{2/ Pneumatic modes:}

- Pneumatic motor mode: the compressed air is injected in the engine to generate torque. The CV timing controls the torque load (Figure 5).

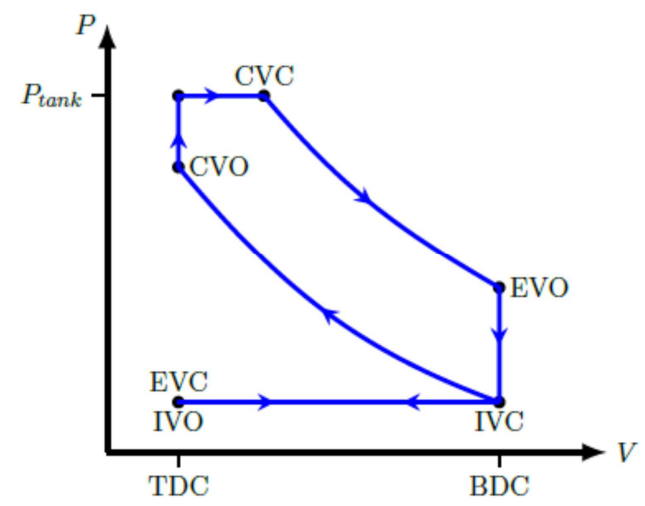

Figure 5 : P-V diagram of the pneumatic pump mode

- Pneumatic pump mode: the air tank can be charged during braking using the pistons to pump the air back in the tank. The charge valve timing is controlling the braking 

(Figure 6)

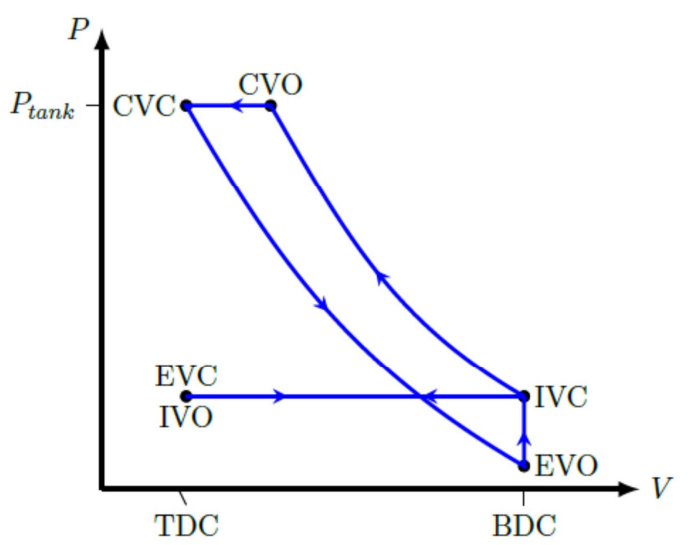

Figure $6:$ P-V diagram of the pneumatic motor mode The hybrid pneumatic powertrain has 3 modes: thermal traction with torque generation in conventional combustion mode, pneumatic traction with torque generation in pneumatic motor mode, regenerative braking with torque recuperation in pneumatic pump mode. Unlike with the parallel thermal electric, the two energy sources never operate simultaneously. The modeled engine is a $1.21 \mathrm{NA}$ gasoline engine, $60 \mathrm{~kW}$, operating on 4 strokes. Fuel is cut off during the pneumatic modes. No supercharging or undercharging modes are considered. For low complexity and low cost reasons, the mechanical valve train from the original engine is conserved and the $\mathrm{CV}$ is assumed to be electromagnetic. The hybrid pneumatic gasoline engine is integrated in a C-Segment vehicle. To give flexibility of the model for optimization approaches, the original manual gear box (MGB) is replaced by a continuously variable transmission (CVT). The advantage of the CVT is to adapt the gear ratio to any drive cycle and additional modeled technology - for example a utility for waste heat recovery. The powertrain model is enough flexible and simplified to suit in the future for an optimization study. The model flowchart is presented in the Figure 7: 


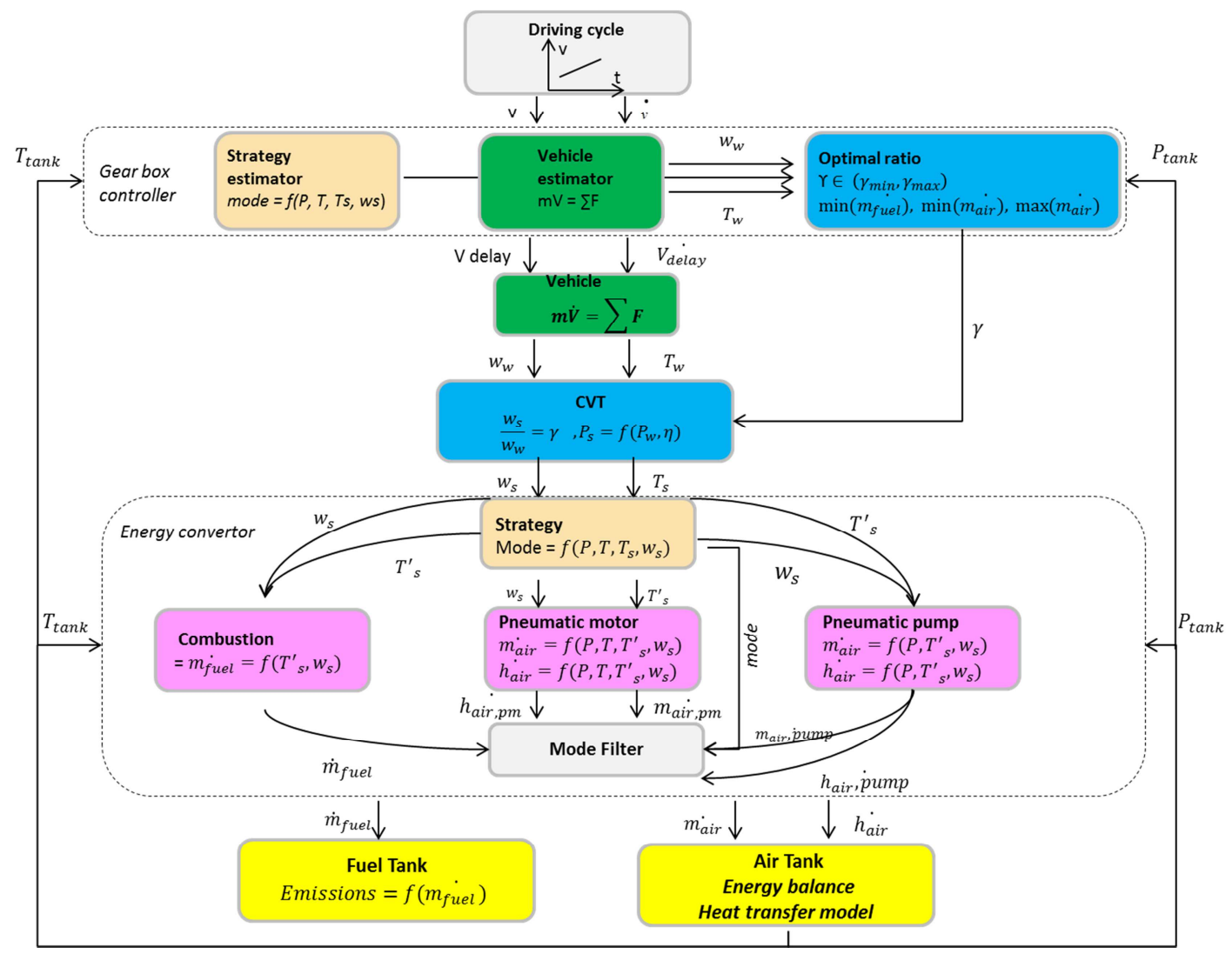

Figure 7 : Hybrid pneumatic engine model flowchart

The three engine operating modes are represented in the engine bloc. The combustion and the pneumatic modes are described by maps. The pneumatic maps are results from simulations. These maps consider the kinematics of the air transfer through the engine, the charge valve timing and the exchanged heat between the pistons and the cylinder wall. They are the efficiency and COP evolution as a function of the air tank pressure and temperature and the torque usage. An example of pneumatic maps for small NA gasoline engine can be found in [6].

The model uses a mode strategy to determine the optimal operating mode between pneumatic motor mode and combustion mode. The strategy is based on feasibility and stability conditions. If they are satisfied then the pneumatic mode is used. The feasibility conditions are related to the available compressed air in the tank. The stability condition is introduced to avoid the frequent transient between combustion and pneumatic modes. This can be modeled by an additional cost function $g_{k}\left(x_{k}, u_{k}\right)$, including the fuel energy consumed and a special factor. The cost of the fuel consumption is compared with the energy contained in the fuel.

$\sum g_{k}\left(x_{k}, u_{k}\right) \leq L H V * \sum m_{f u e l}\left(x_{k}, u_{k}\right)(1)$

Using the pneumatic pump is always preferred over the disc brakes as long as it is feasible. The pump mode conditions are:

$T_{s}<0(2)-$ deceleration condition

$P_{\tan k} \leq P_{\tan k, \max }(3)$ - air tank saturation condition 
The model of the air tank computes the tank temperature and pressure from the air flow rate $\dot{m}_{\text {air }}$ and the enthalpy flow rate $\dot{h}_{\text {air }}$. The following equations are used in the model:

The pressure $P_{\text {air }}$ can be calculated with equation 6 , which is the state equation for the perfect gas.

$$
\text { - Ideal gas law } P_{\text {air }}=\frac{m_{\text {air }} * r_{\text {air }} * T_{\text {air }}}{V_{\tan k}}
$$

The temperature of the air $T_{\text {air }}$ is determined by the following differential equation, where the air volume is considered constant:

- Energy balance of the tank $m_{\text {air }} * c_{v, \text { air }}\left(T_{\text {air }}\right) * \frac{d T_{\text {air }}}{d t}=\dot{h}+\phi_{\text {int }}(5)$

The heat flow $\phi_{\text {int }}$ between the air and the wall is determined by the equation 6 .

- Heat rate between the air and the inner wall $\phi_{\text {int }}=h_{\text {int }} * A_{c y l}\left(T_{\text {wall }}-T_{\text {air }}\right)(6)$

The temperature $T_{\text {wall }}$ of the wall is determined by the equation 7 , which puts a thermal inertia in the model.

- Tank wall energy balance $\phi_{\text {ext }}-\phi_{\text {int }}=m_{\text {wall }} * c_{p, \text { wall }} * \frac{d T_{\text {wall }}}{d t}$

And finally the heat flux coming from the exterior the wall of the air tank is given by the equation 8.

- Heat rate between air and outer tank wall $\phi_{\text {ext }}=h_{\text {ext }} * A_{c y l} *\left(T_{\text {ext }}-T_{\text {wall }}\right)$

The specific heat capacity of the wall is fixed. The mass of the wall $\mathrm{m}_{\text {wall }}$ is calculated knowing its thickness and its volume and a density of the wall $-\rho_{\text {wall }}=7800 \mathrm{~kg} / \mathrm{m}^{3}$.

$T_{\text {air }}, T_{\text {wall }}, T_{\text {ext }}$ are respectively the air temperature inside the tank, the tank wall temperature and the ambient air temperature. $m_{\text {air }}$ and $m_{\text {wall }}$ are the mass of air inside the tank and the wall mass. $r_{a i r}$ is the specific gas constant, $c_{p, a i r}$ is the specific heat capacity of the air, $c_{v, a i r}$ is the volumetric heat capacity of the air. $c_{p \text {,wall }}$ is the specific heat capacity of the wall. $h_{\text {int }}$ is the heat transfer coefficient between the inner wall of the tank and the air inside the tank.

The air tank is a stainless steel, and it is a cylinder with a radius 3 times smaller than its length. The air temperature in the tank is homogeneous. The admissible pressure is between $P_{\min }=5 \mathrm{bar}$ and $P_{\max }=20 \mathrm{bar}$. The admissible temperature is between $300 \mathrm{k}$ and $1000 \mathrm{~K}$. These limits come from the ranges of the pneumatic pump and motor maps. The CVT chooses the optimal powertrain efficiency taking into account the combustion and the pneumatic modes. For combustion mode the selected gear ratio gives the minimal fuel consumption on the isopower. For pneumatic modes the selected ratio allows maximum charging for the air tank and the torque for the pneumatic motor.

Table 1 sums the vehicle characteristics for simulation:

Table 1 : C segment vehicle characteristics for simulation 


\begin{tabular}{|c|c|c|}
\hline Sub-System & Characteristic & Value \\
\hline Vehicle & Nominal mass [kg] & 1075 \\
\hline \multirow[t]{2}{*}{ Gear box } & CVT efficiency [-][18] & 0.84 \\
\hline & MGB efficiency [-] & 0.95 \\
\hline \multirow[t]{8}{*}{ Engine } & Displacement [I] & 1.2 \\
\hline & Number of cylinder & 3 \\
\hline & Rated power [kW] & 60 \\
\hline & Max. speed [rpm] & 6000 \\
\hline & Max. Torque [Nm] & 120 \\
\hline & Idle speed [rpm] & 950 \\
\hline & Idle fuel consumption [I/h] & 0.33 \\
\hline & Deceleration Fuel cut- off & Yes \\
\hline \multirow[t]{3}{*}{ Fuel } & Type & Gasoline \\
\hline & Density $[\mathrm{kg} / \mathrm{l}]$ & 0.795 \\
\hline & Lower heating value $[\mathrm{MJ} / \mathrm{kg}]$ & 42.7 \\
\hline \multirow{11}{*}{$\begin{array}{l}\text { Pneumatic Motor } \\
\text { and Pump } \\
\text { Air tank }\end{array}$} & Minimum speed [rpm] & 200 \\
\hline & Maximum speed [rpm] & 3000 \\
\hline & Volume [I] & 50 \\
\hline & Steel wall thickness [mm] & 4 \\
\hline & $c_{p, \text { wall }}[\mathrm{J} / \mathrm{kgK}]$ & 5 \\
\hline & $h_{\text {int }}\left[\mathrm{W} / \mathrm{m}^{2} \mathrm{~K}\right]$ & 5 \\
\hline & $h_{\text {out }}\left[\mathrm{W} / \mathrm{m}^{2} \mathrm{~K}\right]$ & 5 \\
\hline & Minimum pressure [bar] & 5 \\
\hline & Maximum pressure [bar] & 20 \\
\hline & Initial pressure [bar] & 4 \\
\hline & Initial temperature $\left[{ }^{\circ} \mathrm{C}\right]$ & 25 \\
\hline Ambient air & Temperature $\left[{ }^{\circ} \mathrm{C}\right]$ & 25 \\
\hline
\end{tabular}

\section{Results:}

At first the simulation model is run in conventional ICE mode. The results are illustrated in Table 2.

Table 2 : Simulation results on NEDC for model calibration.

\begin{tabular}{lc}
\hline C-Segment Vehicle & Simulated \\
\hline Emissions $\mathrm{CO}_{2}[\mathrm{~g} / \mathrm{km}]$ with MGB & 103 \\
Emissions $\mathrm{CO}_{2}[\mathrm{~g} / \mathrm{km}]$ with CVT & 113 \\
\hline
\end{tabular}

In order to estimate how efficient the CVT is on the C-Segment vehicle the simulation is launched on the 1.21 NA engine. The results are presented in Table 2. The CVT efficiency is $84 \%$ and the gear ratios are between 1.53 and 9.15 . The consumption points have moved along its respective iso-power line, towards the optimal consumption point. Nonetheless the result shows an increase in emissions in comparison of the manual gear box. This can be explained by the lower efficiency of the CVT in comparison of the MGB, and because of the small size of the engine 1.21, many of the consumption point with the manual gear box are already quite close to the optimal points. Thus the loss in transmission efficiency is greater that the gain on ICE efficiency.

The described modes of the hybrid pneumatic engine are represented on the NEDC (Figure 8). The fuel is cut off in the idle phases. During the first seconds of the accelerations, the torque is delivered from the pneumatic mode of the engine, this means without fuel injections and just from the compressed air in the tank. The torque in the pneumatic motor mode can reach almost $40 \mathrm{Nm}$. The pneumatic motor mode is frequently used in the urban part of the NEDC. 
During the deceleration phases the engine is working in pump mode and the compressed air is stored in the air tank. The extra- urban part of the cycle requires higher torque to follow the high speed part of the cycle and the torque is provided totally from the internal combustion mode of the engine. The three deceleration phases in the end of the cycle contribute to charge the air tank with compressed air.

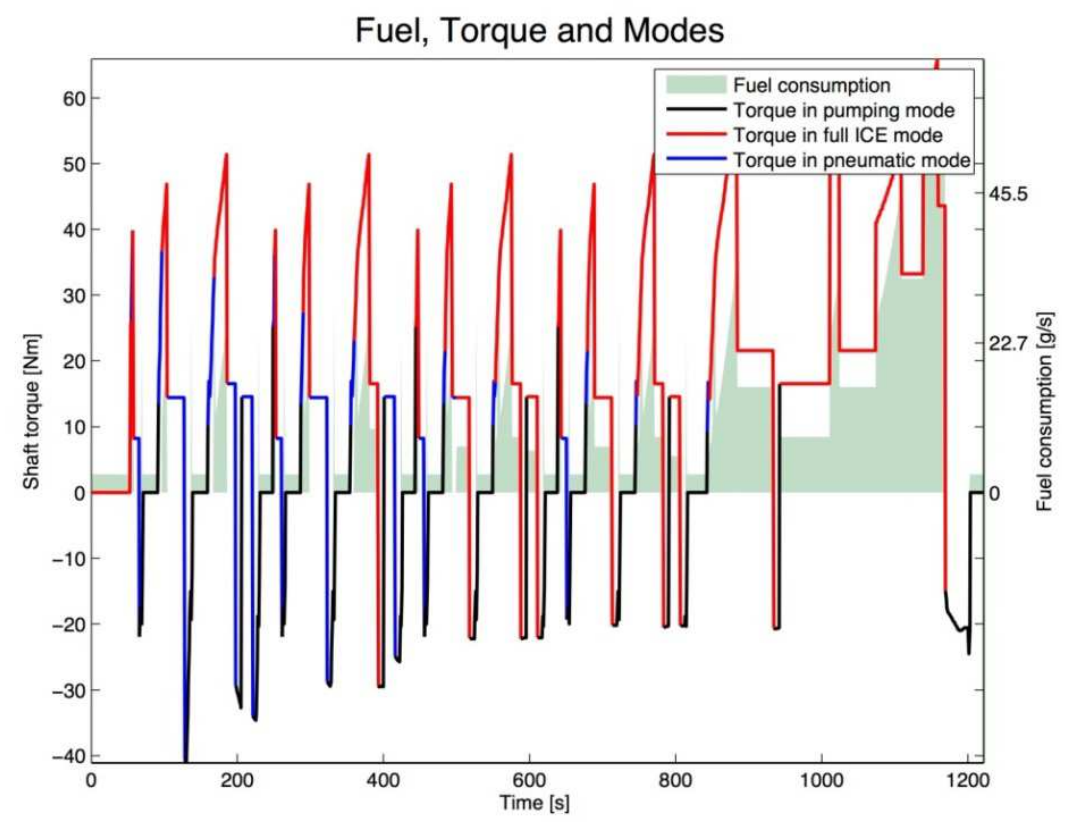

Figure 8 : Hybrid pneumatic engine modes in NEDC, C- Segment vehicle, 1.21 NA engine, CVT mode

The $\mathrm{CO}_{2}$ emissions on NEDC with hybrid pneumatic engine are $91 \mathrm{~g} / \mathrm{km}$ (with CVT), which is representing a fuel consumption improvement of $20 \%$ in comparison with normal thermal powertrain. From the analysis of Figure 8 one concludes that the hybrid pneumatic engine suits for urban drives, characterised by low speed demand and strong transient behaviour. On NEDC the hybrid pneumatic engine acts as mild hybrid system and can be considered as stop and start system. The deceleration energy during the urban drives (the first part of the cycle) is used to charge the air tank. The deceleration energy is converted into pneumatic and stored in the air tank. According to the mode strategy, related to the tank pressure level, the pneumatic motor mode is converting the pneumatic energy into acceleration energy.

Around $30 \%$ of the kinetic deceleration energy is available to be used to pump the air in the tank. The difference between the total vehicle deceleration energy and the amount that is available as indicated deceleration energy in the pump is explained by several losses of the kinetic energy during deceleration. The losses are due to the aerodynamic and rolling resistance forces of the vehicle, to the transmission efficiency, the mechanical friction of the engine and the losses between the engine and the air tank.

For NEDC the indicated deceleration energy available for the pneumatic pump mode is representing $30 \%$ of the total vehicle deceleration energy. The evolution of the deceleration through the vehicle powertrain is represented in the Figure 9. 




Figure 9 : Evolution of the deceleration energy from the vehicle to the air tank

The losses of the deceleration energy are decomposed on the following diagram (Figure 10):



Figure 10: Losses of the deceleration energy

The losses due to the aerodynamic and rolling resistances of the vehicle are function of the speed and the change of speed. They are representing 37\% and increase at high speeds. The losses due to the mechanical friction of the engine are high at low vehicle speed and represent for this case around $30 \%$.

The potential of the hybrid pneumatic engine is tested on urban drive. For that a special urban cycle is designed. The urban drive profile is obtained by randomly choosing from the three low speed parts of the WLTP cycle (from 0 to $600 \mathrm{~s}$ ). The obtained speed profile is illustrated in Figure 12, and the general characteristics are given in Table 3: 


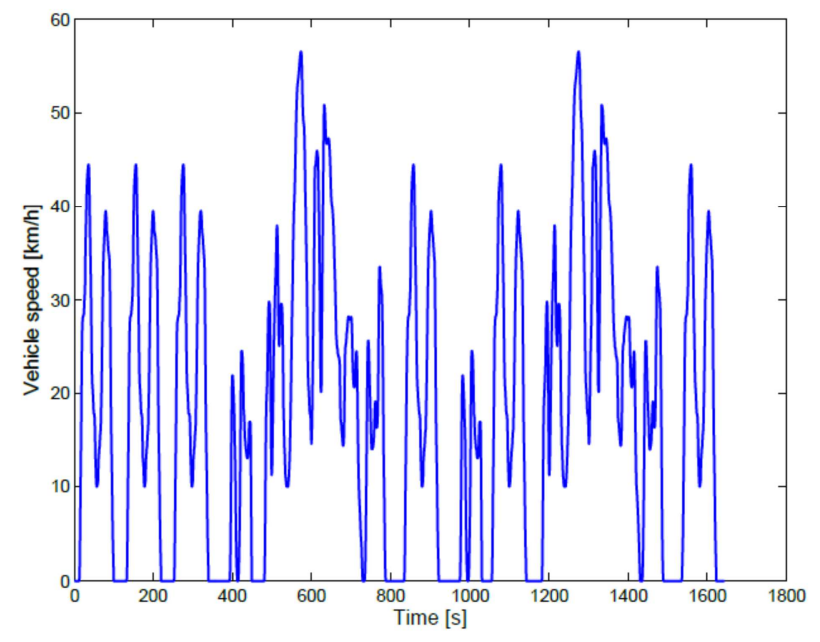

Figure 8 : Urban drive profile

Table 3: Urban cycle characteristics

\begin{tabular}{lllll}
\hline Distance $[\mathrm{km}]$ & Duration $[\mathrm{s}]$ & $\begin{array}{l}\text { Avg. speed } \\
{[\mathrm{km} / \mathrm{h}]}\end{array}$ & $\begin{array}{l}\text { Min acceleration } \\
{\left[\mathrm{m} / \mathrm{s}^{2}\right]}\end{array}$ & Max acceleration $\left[\mathrm{m} / \mathrm{s}^{2}\right]$ \\
\hline 8.5 & 1644 & 28.8 & -1.5 & 1.7 \\
\hline
\end{tabular}

Figure 12 illustrates the hybrid pneumatic powertrain modes on urban drive. The tank pressure and temperature evolutions are shown in Figure 14. The urban drive starts with discharged air tank, only 4 bars pressure and during the first 50 seconds of the cycle the tank is charged till reaching 12 bars pressure. In this moment the first pneumatic motor mode is provided in the cycle. The power of the shaft reaches $11 \mathrm{~kW}$. In the period of the cycle, between 200s and 600s the tank pressure increases progressively from 11 bars to 15 bars and the engine pneumatic mode acts in all idle and first acceleration phases, delivering maximal power of $24 \mathrm{~kW}$ on 240 seconds. Because of the lower initial pressure in the tank, the pumping mode starts after the first strong deceleration at around 50 seconds of time.

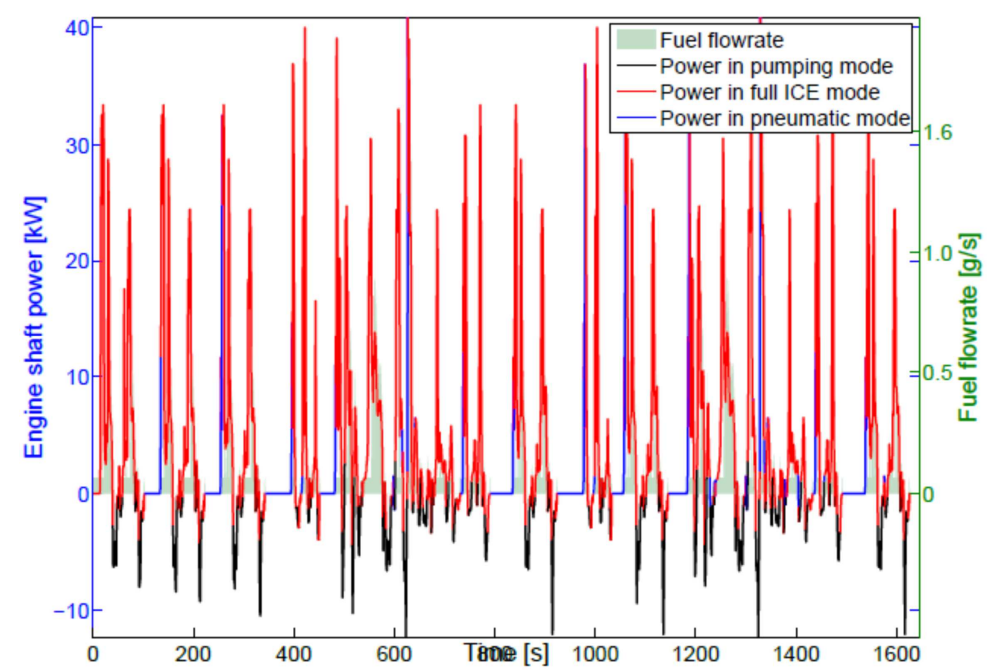

Figure 9 : Torque repartition and fuel consumption, urban cycle 


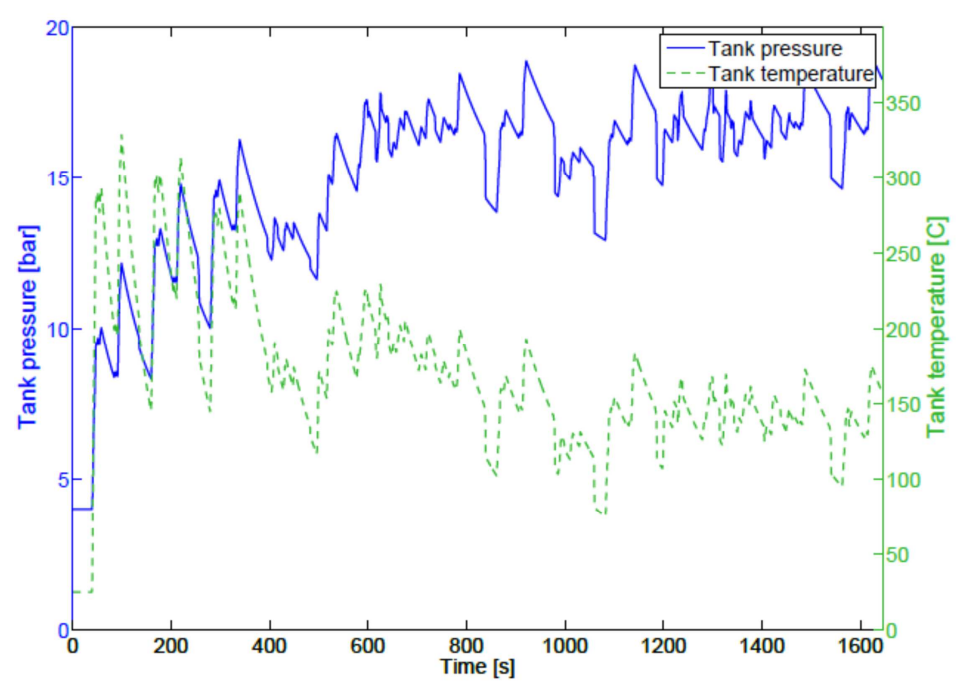

Figure 10 : Tank pressure and temperature, urban cycle

The transient behaviour of the urban cycle between acceleration and deceleration establishes a sequence (from $600 \mathrm{~s}$ to $1600 \mathrm{~s}$ ) where the tank pressure during charging and discharging is oscillating between 14 bars and 18 bars. The pneumatic motor mode is used in all idle and first acceleration phases, covering speeds demands till $40 \mathrm{~km} / \mathrm{h}$. In the entire pneumatic motor mode the fuel is cut off. The conventional engine combustion mode is used to cover the rest of the energy demand by burning fuel. In the beginning of the cycle with the first pumping modes the pressure and the temperature in the tank grow up. The tank is not considered adiabatic and because the air is with high temperature (Figure 13) it needs to be insulated. When the tank is discharged during the pneumatic motor modes, with the decreasing pressure and the decreasing mass in the volume, the temperature in the tank also decreases. The air tank pressure and temperature are related by the ideal gas relation and the volume of the tank is considered remaining constant at 50 liters. The feasibility of the concept is related to the capacity to maintain the enthalpy (energy) in the tank and not to lose it through the walls. The simulation is done with a tank with fixed volume of 50 liters.

Finally comparing the fuel emissions to those of the C-Segment vehicle equipped with purely thermal powertrain (Table 2), the HPE powertrain suits very well to urban drive, because the fuel consumption emissions are reduced with $47 \%$ to only $51 \mathrm{~g} \mathrm{CO}_{2} / \mathrm{km}$ (Table 4). On NEDC the HPE powertrain improvement of the $\mathrm{CO}_{2}$ emissions is $20 \%$ (Table 4). The simulations are performed with CVT.

Table 4: Fuel consumption simulation results

\begin{tabular}{lcc}
\hline C-Segment Vehicle & Urban cycle & NEDC \\
\hline Emissions $\mathrm{CO}_{2}[\mathrm{~g} / \mathrm{km}]$ with thermal powertrain & 98 & 113 \\
Emissions $\mathrm{CO}_{2}[\mathrm{~g} / \mathrm{km}]$ with HPE powertrain & 51 & 91 \\
\hline
\end{tabular}

The significant improvement for the urban cycle is logical because the pneumatic storage systems have a high specific power and medium to low specific energy [2] (Figure 14). The HPP is a situated in the left high corner on the Ragone Diagram, similarly to the others mechanical storage systems. 


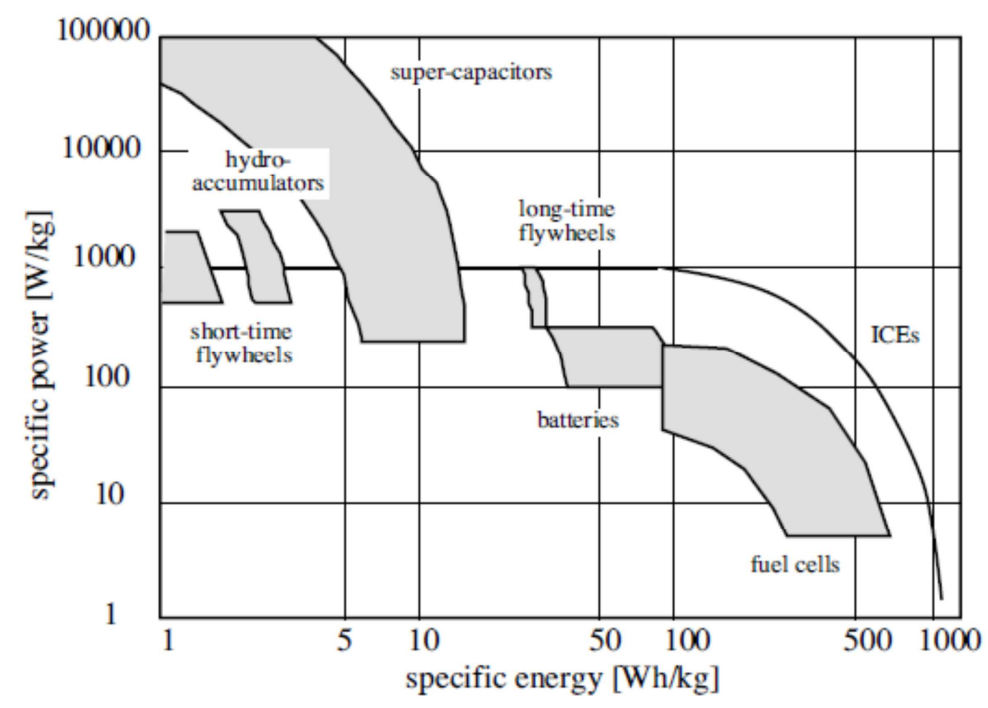

Figure 14: Specific power versus specific energy for various short-term energy storage systems [6]

Their fast charge and discharge characteristics are thus suitable for the rapid accelerations and decelerations of the urban cycle. One can note that even with initial tank pressure of 4 bars, the quick succession of braking during the first 100 seconds of the cycle is enough to raise the pressure to 10 bars. This pressure level is sufficiently high to start using the engine in pneumatic motor mode. For NEDC similar behavior is observed for the urban part, for the extra urban section of NEDC the pneumatic motor mode is almost never used except of occasional power boosts. The highway braking is used to counter thermal losses and keep the tank pressure above 10 bars. The pumping mode is active during the deceleration phases.

\section{Conclusion:}

This article investigates the compressed air as innovative solution for mild hybridization of small gasoline engine. The article presents a concept on a C-Segment vehicle of a hybrid pneumatic powertrain designed as a combination of a conventional internal combustion engine and a short- term pressure storage system. This powertrain presents the advantage to use directly the shaft of the engine to transmit the pneumatic torque, generated from the pneumatic energy source - the compressed air tank. So no specific investment is needed in the powertrain devices, the HPE can be injected in the conventional torque transmission system. The HPE powertrain is simulated on different usages (NEDC and urban) and shows a promising efficiency improvement $-20 \%$ to $50 \%$ (depending on the cycle) and particular low fuel consumption results for the urban usage $-51 \mathrm{~g} \mathrm{CO}_{2} / \mathrm{km}$. The concept suits very well for urban usage. For the C-Segment vehicle class, the hybrid pneumatic powertrain presents an interesting economic alternative for hybridization to the hybrid electric vehicle.

The presented model of hybrid pneumatic powertrain can be used in optimization studies for optimal mode control or for optimal pneumatic powertrain design. The model is applied on an energy integration study of the small scale organic rankine cycle on a C-Segment vehicle with small gasoline engine. The association of the hybrid pneumatic mode, whit a short term energy storage system and the waste heat recovery is interesting concept for energy recovery. The association of the two energy recovery technologies brings an additional fuel consumption benefits. 
C-segment is a car size classification defined by the European Commission as the thirdsmallest segment (above the A-segment and B-segment) in the European market. The Csegment corresponds approximately to the Compact Car segment in North America and the Small Family Car in British English terminology [19].

\section{Appendix 2:}

Hybrid- electric vehicles differ according to the degree of hybridization of the powertrain (Figure 3), and the battery capacity. The solutions are classified according to the functional classification in Figure 1.

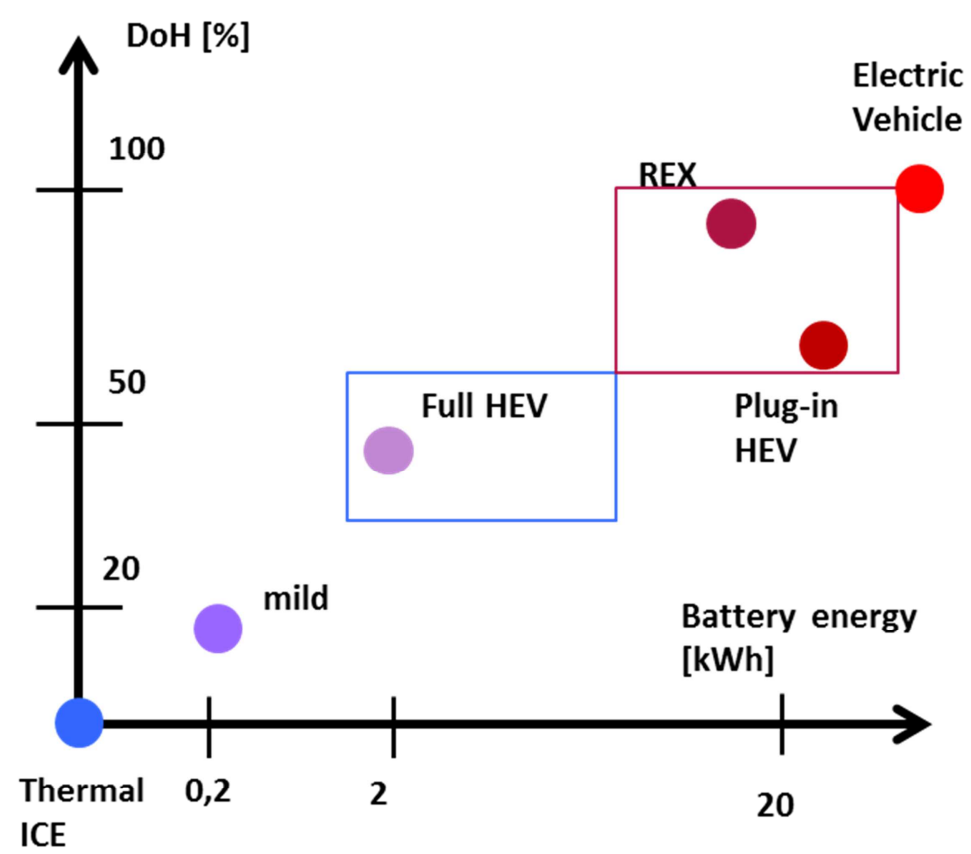

Figure 2.1: Functional classification of HEVs in term of degree of hybridization and battery capacity [6]

Depending of their physical configuration, hybrids can be classified in terms of degree of hybridization [6]

The simplest (parallel) hybridization is the so-called micro hybrid concept, with is essentially an ICE-based powertrain with a small electric motor. Micro hybrids do not required a high battery capacity or complex power electronics, if there are just stop and start. The motor may also act as an alternator for the electrical loads, thus is sometimes referred to as an integrated starter-generator (ISG) [6].

Full hybrids allow all the modes of operation, including power assist, energy recuperation, and purely electric operation. Therefore, they need higher electric power levels leading to the use of high-voltage systems and complex power electronics. The consequent relevant size and weight of the electric components often poses some integration constraints [6]. 
are not well-defined frontiers between these types of HEVs. A more continuous classification is obtained by defining the degree of hybridization, as the ratio between the electric power and the total power:

$$
\operatorname{DoH}=\frac{\mathrm{P}_{\mathrm{b}, \max }}{\mathrm{P}_{\text {ice,max }}+\mathrm{P}_{\mathrm{b}, \max }}
$$

The reduction of energy consumption, but also the additional cost associated with the hybridization, both increase with the degree of hybridization [6].

Two types of HEVs are characterized by a relatively large energy storage system. These HEVs have a larger capability of ZEV operation, with a purely electric range that is similar to that of battery-electric vehicles. In plug-in hybrids the battery can be recharged from the grid, like in BEVs. During driving, the battery can be discharged until a lower limit for battery charge is attained.

\section{References:}

[1] C. Thiel, J. Schmidt, A. Van Zyl, E. Schmid, Cost and well-to-wheel implications of the vehicle fleet $\mathrm{CO} 2$ emission regulation in the European Union, Transportation Research Part A: Policy and Practice, Volume 63, May 2014, Pages 25-42

[2] L. Damiani, M. Repetto, A. Pini Prato, Improvement of powertrain efficiency through energy breakdown analysis, Applied Energy, Volume 121, 15 May 2014, Pages 252-263

[3] Hybrid Vehicles, France, ADEME www.avem.fr/voiture-hybride.html, accessed on 15.04.2015

[4] L. Torres, R. Gonzalez, A. Gimenez, J. Lopez, Energy management strategy for plug-in hybrid electric vehicles. A comparative study, Applied Energy, Volume 113, January 2014, Pages 816-824

[5] Justin D.K. Bishop, Niall P.D. Martin, Adam M. Boies, Cost-effectiveness of alternative powertrains for reduced energy use and $\mathrm{CO} 2$ emissions in passenger vehicles, Applied Energy, Volume 124, 1 July 2014, Pages 44-61

[6] L. Guzzella, A. Scarletta, Vehicle Propulsion Systems - 2013, Springer

[7] L. Guzzella, Ch. Onder, The pneumatic hybridization concept for downsizing and supercharging gasoline engines, MTZ Magazine volume 71, 2010

[8] A. Fazeli, A. Khajepour, C. Devaud, A novel compression strategy for air hybrid engines, Applied Energy, Volume 88, Issue 9, September 2011, Pages 2955-2966

[9] M. Schechter, New cycles for automobiles engines. SAE paper 1999-01-0623 (1999)

[10] P. Higelin, A. Charlet, Y. Chamaillard: Thermodynamic simulations of a hybrid pneumatic - combustion engine concept. International journal of Applied Thermodynamics 5 (1); 1-11 (2002).

[11] C. Dönitz: Hybrid pneumatic engines. Dissertation ETH no. 18761, Swiss Federal Institute of Technology, Zurich, Switzerland (2009)

[12]GuzellaResearch,http://www.idsc.ethz.ch/Research_Guzzella/Automotive_Applications/ Hybrid_Pneumatic_Powertrain, accessed on 23.09.14

[13] Z. Filipi Hydraulic and pneumatic hybrid powertrains for improved fuel economy in vehicles, Alternative Fuels and Advanced Vehicle Technologies for Improved Environmental Performance (2014), 505-540 
427 [14] K. David Huang, Sheng-Chung Tzeng - Development of a hybrid pneumatic-power 428 vehicle Applied Energy (2005), Volume 80, 47-59

429 [15] K. David Huang, Sheng-Chung Tzeng, Wei-Chuan Chang, Energy-saving hybrid vehicle 430 using a pneumatic-power system, Applied Energy (2005), Volume 81, 1-18

431 [16] T.L. Brown, V.P. Atluri, J.P. Schmiedeler A low-cost hybrid drivetrain concept based on compressed air energy storage, Applied Energy (2014), Volume 134, 477-489

433 [17] T. Basbous, R. Younes, A. Ilinca, J. Perron, A new hybrid pneumatic combustion engine 434 to improve fuel consumption of wind-Diesel power system for non-interconnected areas, 435 Applied Energy (2012), Volume 96, 459-476

436 [18] CVT Nissan technology

437 http://www.nissanglobal.com/EN/TECHNOLOGY/OVERVIEW/cvt.html, accessed on $438 \quad 20.10 .14$

439 [19] http://en.wikipedia.org/wiki/C-segment, accessed on 18.02.15 